\title{
LATENT CLASS ANALYSIS OF POST-TRAUMATIC STRESS SYMPTOMS IN CHILD VICTIMS OF SEXUAL ABUSE AND THEIR RESPONSE TO TRAUMA- FOCUSED COGNITIVE BEHAVIORAL THERAPY
}

\author{
* Martine Hébert Ph.D \& Laetitia Mélissande Amédée B.Sc. \\ CIHR IRSC Université du Québec à Montréal
}

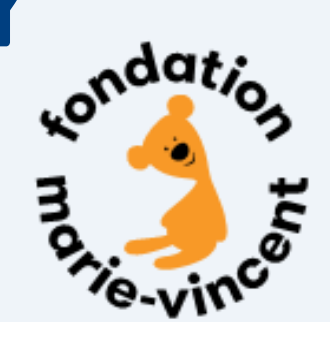

\section{Background}

PTSD symptoms are frequent in child victims of sexual abuse. Yet, authors argued that early trauma could lead to alterations in development that go far beyond the primary symptoms of PTSD and have proposed. Complex PTSD as an alternative diagnosis encompassing difficulties in selfregulation, relationships and selfconcept.

\section{Objectives}

To delineate profiles in child victims of sexual abuse

2 To explore whether profiles are associated with treatment response

\section{Methods}

Sample: 384 children ages 6 to 14, recruited in a Child Advocacy Center in Montreal, Canada.

Analyses: Latent class analysis to identify symptoms profiles at baseline assessment. Paired T-test to assess treatment response.

Measures: Dimensions of Complex PTSD diagnosis as proposed by the IDC-11 were derived from self-report questionnaires.

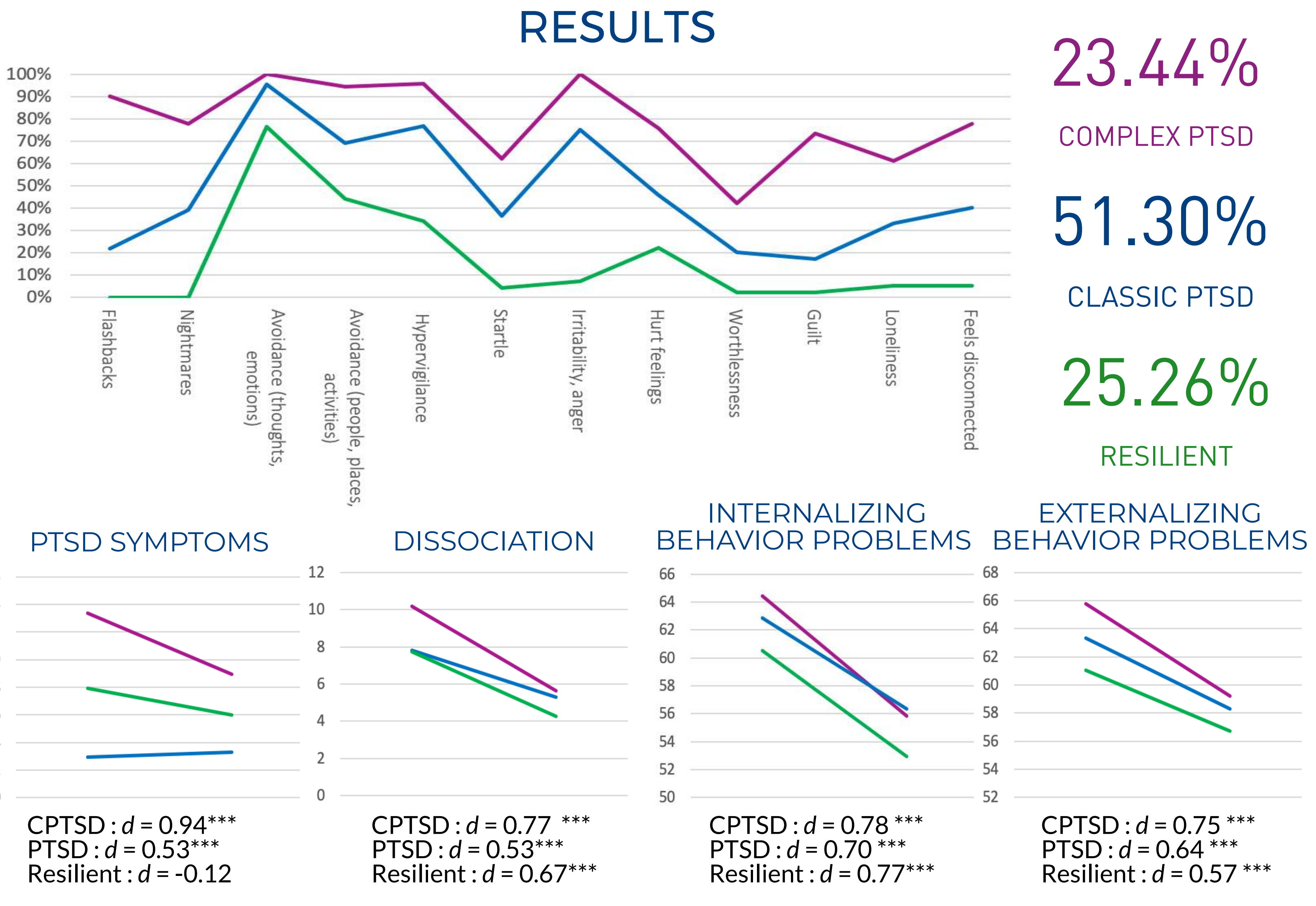

CONCLUSION: The findings highlight the utility of a person-oriented approach to enhance our understanding of the diversity of profiles in child victims. Results offer empirical support for the ICD-11 PTSD and Complex PTSD distinction in a clinical sample of child victims of sexual abuse and the relevance of this distinction in foreseeing treatment outcomes. 